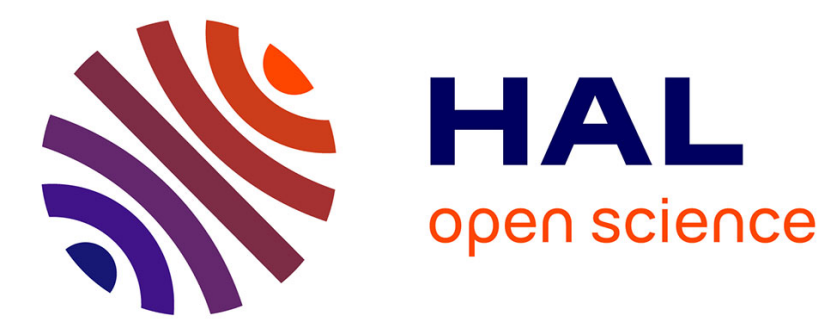

\title{
Mimic Behavior in Home Waste-waters Management Philippe Polomé
}

\section{To cite this version:}

Philippe Polomé. Mimic Behavior in Home Waste-waters Management. 2013. halshs-00855051

\section{HAL Id: halshs-00855051 https://shs.hal.science/halshs-00855051}

Preprint submitted on 28 Aug 2013

HAL is a multi-disciplinary open access archive for the deposit and dissemination of scientific research documents, whether they are published or not. The documents may come from teaching and research institutions in France or abroad, or from public or private research centers.
L'archive ouverte pluridisciplinaire HAL, est destinée au dépôt et à la diffusion de documents scientifiques de niveau recherche, publiés ou non, émanant des établissements d'enseignement et de recherche français ou étrangers, des laboratoires publics ou privés. 
Mimic Behavior in Home Waste-waters Management

Philippe Polomé

August 2013 


\section{GATE Groupe d'Analyse et de Théorie Économique Lyon-St Étienne}

93, chemin des Mouilles 69130 Ecully - France

Tel. +33(0)4 72866060

Fax $+33(0) 472866090$

6, rue Basse des Rives 42023 Saint-Etienne cedex 02 - France

Tel. +33 (0)4 77421960

Fax. +33 (0)4 77421950

Messagerie électronique / Email : gate@gate.cnrs.fr

Téléchargement / Download : http://www.gate.cnrs.fr - Publications / Working Papers 


\title{
Mimic Behavior in Home Waste-waters Management
}

\author{
Philippe Polomé*
}

\begin{abstract}
August 2013
Université de Lyon \& Université Lyon 2, Lyon, F-69007, France ; CNRS, GATE Lyon Saint-Etienne, Ecully, F-69130, France.
\end{abstract}

\begin{abstract}
We present results of a household-level survey on behaviors regarding refuses in the home waste-waters network. Interpreting survey results in a panel-data logit results show that most socio-economic and public good-related respondent's characteristics do not play a significant role in explaining choices to discard in the home waste-waters network. The only significant regressor, apart from the nature of the refuse itself, is, by far, the belief that the respondent has about her neighbors' and relatives' discarding behavior. We use Dong's endogeneity test [7] to show that that regressor is not endogenous. We argue that these results may be used by policymakers to reduce undesirable refuses in the home waste-waters network by means of properly designed nudges.
\end{abstract}

Keywords. Behavior; Endogeneity; Nonparametric; Panel data; Public good; Reputation; Waste-waters.

JEL Classification. Q53 - Water Pollution ; C23 - Models with Panel Data

*E-mail polome@gate.cnrs.fr - http://www.gate.cnrs.fr/spip.php?article44. Helpful comments from L. Campan and C. Hooge from Grand Lyon Metropolitan Area are gratefully acknowledged. Remaining errors are the author's. 


\section{Introduction}

We report results of a household-level survey about how people discard refuses that could potentially be discarded through the home waste-waters network, i.e. sinks and toilets, and whose presence is detected in more or less great amounts in treatment plants. At the same time, it is not very well known where those refuses are coming from : residential, office or service industry areas (e.g. fat from restaurants). These refuses in treatment plants may be costly to handle; they sometimes may not actually be treated by the plant and end up in the natural water system, surface or subterranean (e.g. pharmaceuticals in rivers); they may also clog the sewage system such as e.g. the recent London "Fatberg" [2].

Undesirable refuses in the home waste-waters network are a nonpoint source pollution problem as it is not possible to trace the polluters. Consequently, classical economic instruments of pollution control, i.e. taxes, norms and permits, are not really available to policy makers, even though norms are very common. Selfgovernance solutions as proposed by Oström [15] also do not apply in most cases, at least in urban areas, as coordination costs would surely be prohibitive. The ambient tax solution [18] has never been put into practice and does not seem politically acceptable for home waster-waters. ${ }^{1}$ Even if the problem could one day have a technical or engineering solution by substance detectors and algorithms to trace polluters, it will likely persist for a long time at least locally in less-equipped areas. The Nudge solution [19] might be more efficient. It consists in influencing behaviors using marketing-like messages that are similar to advertising; they may for example be related to a behavioral norm (such as e.g. how much of the population recycle batteries) or to the consequences of one's actions (such as e.g. the pictures on cigarettes packs in some countries), amongst many others. Nudges must be designed and targeted very carefully as they are context-dependent and it is difficult to predict how they might work before funding a public awareness campaign. We present a contribution in that direction.

In this paper, we examine some elements of a person's context that seem to effect her waste-waters behavior. In other words, we seek leverages with which we might expect to influence behavior. Indeed, one may legitimately wonder why more people do not discard more through the home waste-waters network and instead adopt behaviors (recycling or others) that are costly to them, at least in time and effort if not in money. There is an abundant literature in economics on the topic of prosocial behaviors; the Bénabou and Tirole paper [3] has

\footnotetext{
${ }^{1}$ The ambient tax is collected on all potential polluters as soon as a certain set threshold is passed. It is "potential" polluter, not proven polluter, that is, everyone who is connected to the home waste-waters network. If the average pollution level is lower than the threshold, each potential polluter receives a subsidy.
} 
certainly been a milestone in this field and synthesized several approaches, including the well-known Impure Altruism of Andreoni [1]. In that article, the authors emphasize that the prosocial behavior which may appear costly to an outside observer, is actually profitable to their author through the image it gives of her in her social network and vis-à-vis herself. In other words, it does not seem reasonable to imagine that individual behaviors regarding waste are not observed, at least occasionally, by a relatively close network within and outside the household. Therefore, waste behaviors have costs and benefits in terms of social relations and, depending on the circumstances, it may appear useful to adopt the same behavior as the rest of the group or contrarily to dissociate from it, positively or negatively.

In spite of the existence of an EU directive, the 1991 Urban Waste Water Treatment Directive, the literature, not only in economics, but broadly in behavioral sciences, appears rather silent on those behaviors. An OCDE report from 2008 [14] summarizes studies and papers on "Household Behaviors and the Environment"; it has a stated interest in understanding heterogeneity of behaviors and people's "private" and "public" motives. Of interest to the present paper, the report reviews waste generation and residential water use. Regarding waste generation, even though [14] acknowledges 8 household-level data empirical studies on waste generation, all of these papers are concerned with solid waste generation and recycling, and do not address waste-waters. The chapter about residential water use is only concerned about water demand, primarily about the estimation of the price-elasticity of water. Interestingly, the reviewed policy instruments do not seem to include any nudge, at least not in a social sense as we do in the present paper, while on the other hand, they widely acknowledge a low price elasticity of water, thus relatively ineffective policies based on the price of water, in which the price of treatment is often included.

Social interactions have been studied in the case of recycling behavior of solid wastes - a type of behavior typically unobservable to an authority, but at least partially observable by neighbors and relatives. Brekke, Kipperberg, and Nyborg [4] present results from a survey on households' glass recycling indicating that perceived responsibility is a major determinant for reported recycling and that respondents' willingness to accept responsibility for recycling is influenced by beliefs about others' behavior. They also consider uncertainty about others' behavior. Their main psychological theory is one in which individuals self-assign responsibilities - to recycle glass in this case - to contribute to a public good; even though the present study is simpler in many aspects, it is interesting to note that public good motives are absent from our respondents' motives, while imitation is still present. Another major difference between their econometric approach and ours is that they assume exogeneity of the respondents' stated belief in others' (friends and family) recycling behavior (variable $P$ in [4]). 
Ferrara and Missios [8] present cross-country comparative results from OECD cross-section samples of household behavior in 10 countries on municipal solid waste generation and recycling. The policies are primarily about the monetary incentives, that is systems of pricing wastes and how the abundance of recycling services may affect waste generation/prevention. Even though these surveys do not elicit beliefs about others' behaviors, they include a measure of "Importance of desire to be seen as a responsible citizen", which could be revealing reputational motives in the sense of Bénabou and Tirole. Although this measure is used as a regressor for the recycling behavior, its potential endogeneity is not treated.

In the next Section, we summarize the Bénabou-Tirole model of prosocial behavior [3] and adapt it for the (simpler) case of waste-waters behaviors. In Section 3, we present the data and an econometric analysis. The next Section concludes.

\section{A Model of Waste Behavior}

In this section, we briefly present the Bénabou-Tirole [3] model of prosocial behavior as a basis for the econometric specification of Section 3. Bénabou and Tirole observe that a number of individuals might not appear rational at first economic glance because they engage in prosocial behaviors that are clearly costly (in terms of time or effort, or sometimes money) without apparent benefit. They propose that individuals engage in such behaviors following three broad types of incentives : monetary, altruism / "quality" of the public good, and "reputational" with respect to a group or to oneself.

Monetary incentives do not exist in the case of waste-waters because of the nonpoint source nature as indicated in the introduction. Altruism and public good considerations include such motives for an immaterial return of a prosocial action as caring for the well-being of others and/or animals; the "health" of the aquatic environment; or a certain chemical quality of the natural waters in the area. Such motives require, in the case of waster-waters, a fairly good understanding of the water cycle and waste network.

Reputational incentives reflect the benefits that may be derived from the image of ourselves we send to others or to ourselves. The reflection of our own image may include such benefits a self confidence, moral satisfaction or "warm glow" feelings. The image of ourselves we send to others may include a diversity of immaterial motives such as "fitting" in a neighborhood or meeting people, but also more economic motives such as networking (e.g. 
in a job search process). The reputational incentives stem from a partial observationality of the behaviors, e.g. when having friends over or during maintenance works.

Bénabou and Tirole note the possibility of crowding-out between monetary and reputational incentives; that means that the reputational benefits may be reduced when the agent behavior could be interpreted as following the monetary incentives. In other words, for the prosocial behavior to have its full reputational effect, it must also appear disinterested. In terms of waste-waters policy, it means not only that monetary incentives such as penalty fees or subsidies or the ambient tax are difficult to implement due to the nonpoint source nature of the pollution caused by waste-waters, but also they may be inefficient in the sense that they could crowdout reputational benefits. That is to say, if individual waste-waters behaviors do indeed follow reputational incentives, then the efficiency of a public awareness campaign will be undermined by the existence of monetary incentives.

Formally, we summarize Bénabou-Tirole's model, equations (1), (2) and (3) in [3], by writing the individual utility of an effort $a$ (discrete or continuous) of contribution to the public good as

$$
\left(v_{a}+v_{y} y\right) a+x\left(\gamma_{a}-\gamma_{y}\right)-C(a)
$$

where $v_{a}$ and $v_{y}$ are the agent's valuation for contributing to the social good (the "public good" incentive) and for money, respectively; $x$ is the visibility of the behavior; $\gamma_{a}$ is the utility derived from having others observe the behavior and $\gamma_{y}$ is the disutility from having others observe the monetary reward $y$ derived from the behavior. $\gamma_{y}$ appears with a negative sign to underline that agents would prefer to appear disinterested, so that the reputational incentive is $x\left(\gamma_{a}-\gamma_{y}\right) . C(a)$ is the cost of effort $a$, in term of disutility. The model assumes linearity.

In the case of home waste-waters, utility is much simplified as

$$
\mathrm{v}_{a} a+x \gamma_{a}-C(a)
$$

since monetary incentives are not feasible. Crowding-out is therefore not a issue, at least for residential, private individuals, areas. Evidently, we do not observe utility, but we do observe whether the agent discards any particular waste in the home waste-waters network $(a=0)$ or not $(a=1)$, that is, adding an error term $\varepsilon$ to Equation 2 :

$$
\begin{array}{lll}
a=1 & \text { if } & v_{a}+x \gamma_{a}-C(1)>-\varepsilon \\
a=0 & \text { else }
\end{array}
$$


Clearly, we cannot observe $v_{a}, x, \gamma_{a}$ or $C(\cdot)$, but we can examine the significance of regressors that would reveal whether some of these terms are zero. The public good incentives $v_{a}$ might appear through such indicators of knowledge of waste-waters system, e.g. what is the use of a treatment plant? what is the destination of home waste-waters? does the individual has recreational or other use of the aquatic medium? is the person concerned by water pollution issues and does she feel that she can contribute to these issue ? The reputational incentives $x \gamma_{a}$ must necessarily be related to the idea that the agent has of her neighbors or relatives prosocial behaviors. In other words, $x \gamma_{a}$ will be non-zero for an agent $i$ if her opinion of what her friends' or relatives' waste-waters behaviors matter for her own waste-waters behavior. The image of oneself appears difficult to measure without sophisticated psychological tests; we propose to use an indication of a willingness to change one's behaviors about waste as a proxy.

\section{Empirical Analysis}

The data proceed from a survey administered in April and May 2013 on the Saint Priest municipality (part of the Greater Lyon Metropolitan Area, France - GL hereafter). The questionnaire has been designed jointly with GL; it is quite in-depth, so that relatively a lot of information is extracted from each observation, as shown below. The response rate was rather high, around 20 to 30\%, considering that it was not possible to make an appointment beforehand. The respondents chose to participate before knowing the subject of the survey, so that we can exclude sample selection bias. 102 complete and usable questionnaires have been collected ${ }^{2}$, in face to face interviews using a planed sampling procedure designed to avoid all forms of spatial clustering. In spite of its small size, the sample appears quite representative of the municipality in terms of age and gender, somewhat less in terms of professions.

\subsection{Descriptive Statistics}

The main question of the survey was about the behavior of disposal of household refuses that could possibly be discarded by the home waste-waters system. That question is summarized in Table 1.

\footnotetext{
${ }^{2}$ By volunteer trained economics majors, as part of a degree in survey administration and analysis.
} 
Table 1: Question (translated). For each of the following refuse, indicate how you usually discard it. This question is about your own habits; later, we will ask you about what you think neighbors and relatives do.

\begin{tabular}{|l|c|c|c|c|c|c|c|}
\hline Behaviors $(\%) \rightarrow$ & $\begin{array}{c}\text { General } \\
\text { waste bin }\end{array}$ & $\begin{array}{c}\text { Recycling : faci- } \\
\text { lity, retailer, } \\
\text { specialist, } \ldots\end{array}$ & $\begin{array}{c}\text { Home } \\
\text { waste-waters : } \\
\text { sinks, toilets }\end{array}$ & $\begin{array}{c}\text { Exterior } \\
\text { waste-waters: } \\
\text { gutters, sewers }\end{array}$ & $\begin{array}{c}\text { You do } \\
\text { not know }\end{array}$ & $\begin{array}{c}\text { You do } \\
\text { not produce } \\
\text { this refuse }\end{array}$ & Other \\
\hline \hline Cooking fat refuse & 19.61 & 10.78 & 39.22 & 0 & 0.98 & 29.41 & 0 \\
\hline Liquid foodstuffs & 12.75 & 2.94 & 74.51 & 0 & 0 & 8.82 & 0.98 \\
\hline Solid foodstuffs & 91.18 & 2.94 & 0 & 0 & 0 & 3.92 & 1.96 \\
\hline Tea leaves \& coffee & 46.08 & 9.8 & 28.43 & 1.96 & 0 & 2.94 & 10.78 \\
\hline Home cleaning products & 1.96 & 3.92 & 85.29 & 0 & 0 & 6.86 & 1.96 \\
\hline Solvents and paint remnants & 6.86 & 47.06 & 8.82 & 0.98 & 0.98 & 33.33 & 1.96 \\
\hline Phytosanitaries & 2.94 & 9.8 & 0.98 & 1.96 & 0.98 & 81.37 & 1.96 \\
\hline Hydrocarbons & 0 & 63.73 & 0 & 0 & 2.94 & 32.35 & 0.98 \\
\hline Pharmaceuticals & 11.76 & 79.41 & 0.98 & 0 & 0.98 & 5.88 & 0.98 \\
\hline Cosmetics \& hygiene : liquids & 38.24 & 6.86 & 22.55 & 0 & 2.94 & 29.41 & 0 \\
\hline Cosmetics \& hygiene : solids & 88.24 & 1.96 & 0.98 & 0 & 1.96 & 6.86 & 0 \\
\hline Toilet paper rolls & 54.9 & 25.49 & 18.63 & 0 & 0 & 0.98 & 0 \\
\hline Cigarette stubs & 25.49 & 0 & 0.98 & 0.98 & 0 & 69.61 & 2.94 \\
\hline Soil, sand or similar & 11.76 & 17.65 & 0 & 3.92 & 1.96 & 46.08 & 18.63 \\
\hline
\end{tabular}

The row and column titles are summarized for presentation; they are more complete and less technical in the questionnaire.

Table 1 shows that respondents are well aware of what their household does with each type of waste as there are very few "don't know" or "other/unspecified" answers. Those wastes that are discarded via the external network are also marginal. Depending on the waste category, the three main ways of discarding are the general waste bin (0 to $91 \%)$, the recycling bin (0 to $79 \%$ ), or the home waste-waters system (0 to $85 \%)$. Seven categories of waste are never (or 1\%) discharged into the home network: Solid foodstuffs, Phytosanitaries, Hydrocarbons, Pharmaceuticals, Cosmetics \& hygiene : solids, Cigarette stubs and Soil/sand. With the exception of Toilet paper rolls, solids are never discarded through the home network.

Respondents answered these questions sequentially. Unfortunately, it was not possible to rotate the questions : all the respondents answer the items in the same order.

\subsection{Econometric Model}

The sequential nature of the responses in Table 1 is reminiscent of a panel-data model : it is as if each individual was observed several times, once for each type of waste. Presumably there is a correlation between waste behaviors, for example, one might think that some people may prefer recycling any waste wherever possible. The panel-data model, at least the random-effects, assumes that the correlation is the same among all wastes and respondents (equicorrelation, see Cameron and Trivedi [6]). Formally, following e.g. [6], Equation 3 and 
the panel data set jointly define a logit panel-data model :

$$
\operatorname{Pr}\left\{y_{i t}=1 \mid \alpha_{i}, \beta\right\}=\frac{\exp \left(\alpha_{i}+x_{i t} \beta\right)}{1+\exp \left(\alpha_{i}+x_{i t} \beta\right)}=\Lambda\left(\alpha_{i}+x_{i t} \beta\right)
$$

where $y_{i t}=1$ if respondent $i$ chooses to discard waste $t$ in the home waste-wasters system, and $y_{i t}=0$ otherwise; $x_{i t}$ is a vector of regressors; $\alpha_{i}$ is the respondent's specific effect and $\beta$ is a vector of unknown coefficients. As a first approach, we consider fixed effects versus random effects. The Hausman test [9] indicates unequivocally an absence of endogeneity on the $\alpha_{i}$; therefore, we prefer the random-effects model. Such model cannot benefit from a treatment of heteroskedasticity, see Cameron and Trivedi [6].

Regressors are grouped following our interpretation 3 of the Bénabou-Tirole model [3]. The results are presented in Table 2 for the "chemical" wastes of Table 1, that is 707 observations for 101 respondents. We focused on the "chemical" wastes because it seemed intuitive to consider relatively homogenous refuses.

Table 2: Probability to reject in home waste-waters network various "chemical" wastes. Random-effects Panel data logit.

\begin{tabular}{|c|c|c|c|c|c|c|}
\hline \multicolumn{2}{|c|}{ Reject in home waste-waters network (1/0) } & Type & $\hat{\beta}$ & p-value & $\hat{\beta}$ & p-value \\
\hline \multirow{7}{*}{ Waste type } & Ref $=$ Home cleaning products & Inter. & 3.41 & 0.10 & 1.26 & 0.61 \\
\hline & Solvents and paints & Dich. & -4.74 & 0.00 & -4.47 & 0.00 \\
\hline & Phytosanitaries & Dich. & -7.12 & 0.00 & -6.19 & 0.00 \\
\hline & Hydrocarbons & Dich. & -25.59 & 1.00 & -22.41 & 1.00 \\
\hline & Pharmaceuticals & Dich. & -7.12 & 0.00 & -5.82 & 0.00 \\
\hline & Cosmetics \& hygiene : liquids & Dich. & -7.12 & 0.00 & -6.17 & 0.00 \\
\hline & Cosmetics \& hygiene : solids & Dich. & -3.57 & 0.00 & -3.15 & 0.00 \\
\hline \multirow{8}{*}{ Socioecon. } & Age & Cont. & -0.05 & 0.44 & -0.01 & 0.94 \\
\hline & $\mathrm{Age}^{2}$ & Cont. & 0.00 & 0.27 & 0.00 & 0.63 \\
\hline & Sex & Dich. & -0.16 & 0.69 & -0.12 & 0.80 \\
\hline & Higher education & Dich. & 0.54 & 0.27 & 0.39 & 0.49 \\
\hline & Child(ren) younger than 7 & Dich. & -0.70 & 0.18 & -0.14 & 0.82 \\
\hline & Homeowner & Dich. & -0.17 & 0.69 & -0.35 & 0.50 \\
\hline & Lives in an apartments building & Dich. & 0.08 & 0.87 & -0.17 & 0.78 \\
\hline & Has no pet & Dich. & -0.58 & 0.19 & -0.59 & 0.26 \\
\hline \multirow{5}{*}{ Public $v_{a}$} & Lived a long time in the region & Dich. & -0.10 & 0.81 & 0.09 & 0.86 \\
\hline & Knows what treatment plants are for & Dich. & 0.56 & 0.18 & 0.50 & 0.32 \\
\hline & Knows if home network connect to treat. plant & Dich. & 0.13 & 0.76 & -0.22 & 0.66 \\
\hline & Worried by water pollution & Dich. & -0.76 & 0.13 & -0.90 & 0.13 \\
\hline & Has water-based leisures & Dich. & 0.47 & 0.28 & -0.11 & 0.83 \\
\hline \multirow{2}{*}{ Reput. $x \gamma_{a}$} & Ready to change habits & Dich. & -0.35 & 0.43 & -0.83 & 0.12 \\
\hline & Neighbors reject same waste in home network & Dich. & & & 0.98 & 0.00 \\
\hline & & & & $95 \%$ conf. & & $95 \%$ conf. \\
\hline \multicolumn{3}{|l|}{ Variance $\alpha_{i}$} & 0.63 & {$[.14-2.81]$} & 0.84 & {$[.26-2.74]$} \\
\hline \multicolumn{3}{|c|}{$\rho$ correlation between waste behaviors } & 0.11 & {$[.006-.71]$} & 0.18 & {$[.02-.70]$} \\
\hline \multicolumn{3}{|c|}{ LR Test $\rho=0$ (p-value $)$} & & 0.227 & & 0.15 \\
\hline
\end{tabular}


Table 2 shows very different intercepts for each type of waste, as might be expected from Table 1 on behaviors. The probability of discarding in the home network changes dramatically (from about $85 \%$ to virtually $0 \%$ ) and highly significantly (p-values near zero) for each waste type; the exception being hydrocarbons, maybe because there is only one respondent who releases hydrocarbons in the home network.

None of the classical socio-economic variable is significant (p-value well above the 0.05 threshold): age, gender, education, family composition, presence of pet, home ownership. But also the regressors associated with the $v_{a}$ term in the Equation 3, that is those that could indicate "public good / altruism" motivated respondents such as the respondent's Knowledge of the waste-waters system, Time span living in the region, Type of housing, Having water-based recreational activities or Sensitivity to water pollution issues have no influence, or in any case, no influence that is similar among all respondents. The latter, Sensitivity to water pollution issues, is actually close to significance (p-value slightly above the 0.10 threshold), with a negative sign as might be expected. We defer the discussion of the regressors associated with the $x \gamma_{a}$ term in the Equation 3, corresponding to the "reputation" motives of the Bénabou and Tirole model to the next section.

\subsection{Endogeneity}

Table 2 presents the results of two regressions, one including the dichotomous variable "Neighbors (including relatives) reject same waste in home network". This variable takes the value one if the respondent believes that neighbors and relatives discard the corresponding waste in the home waste-waters network; we call this variable "mimic" for short. The mimic regressor is certainly striking as potentially endogenous in the sense that it may be governed by the same, possibly unobserved, variables as our variable of interest (Reject in home waste-waters network). The endogeneity stems from the fact that respondents might rationalize or justify their behavior by stating that they are not worse or better than their relatives.

We consider two approaches to this issue. The first is to realize that endogeneity may cause inconsistency of the panel logit estimator and thus a risk that the coefficients of the other regressors be different with and without the mimic regressor. Since the estimated coefficients for the other regressors appear generally stable between the two regressions, it implies that at least these results are robust to the possible presence of endogeneity, but it is also a hint that endogeneity may not be an issue. 
Testing endogeneity in this context is difficult as there is no obvious instrument and thus the classical Hausman test [9] is not available. Dong [7] presents a way of testing for endogeneity in a binary choice model without instrument. Following Dong [7], consider a binary choice model

$$
D=I\left(\alpha+X^{\prime} \beta+Y \gamma+\varepsilon \geq 0\right)
$$

with $I(\cdot)$ is one if its argument is true and zero otherwise; $D$ is the "Reject in home waste-waters network" dummy dependent variable; $\varepsilon$ is a mean zero error with a possibly unknown distribution; $X$ is a vector of exogenous regressors; and $Y$ is the mimic endogenous regressor. Let $Y$ be determined as

$$
Y=G(X)+U
$$

where $U$ has an unknown distribution and $G$ is an unknown nonlinear function. Model 6 is therefore nonparametric. As noted in Dong [7], endogeneity of $Y$ comes from correlation between $\varepsilon$ and $U$. If an element of $\beta$ is zero (an exclusion restriction), the corresponding covariate in $X$ would be an instrument, enabling identification. Without exclusion restriction, to identify Model 5, Dong shows that $G$ must be nonlinear in $X$ and that we must assume $\varepsilon=\lambda U+V$ where $\lambda$ is some unknown constant and the error $V$ is independent of $U$ and $X$. Because $Y$, the mimic regressor, is a dichotomous variable in our application, we may safely assume nonlinearity of Model 6 as function $G(\cdot)$ should behave as a kernel function.

To implement the approach, we estimate Model 6 by a kernel (thus nonlinear) regression technique, from which we compute $\hat{U}$ as the vector of residuals. Then we substitute $\varepsilon$ for $\lambda \hat{U}+V$ in Model 5

$$
D=I\left(\alpha+X^{\prime} \beta+Y \gamma+\lambda \hat{U}+V \geq 0\right)
$$

which is then corrected for endogeneity as the endogenous error term $\varepsilon$ is replaced by the sum of an observed variable $\hat{U}$ that contains the correlation with $Y$, and an uncorrelated error $V$. In other words, the approach introduces a regressor $\hat{U}$ that effectively removes the endogeneity of the model. Consequently, if $\hat{U}$ is not significant in Model 7, it means that $Y$ was not endogenous in the first place.

We used the smooth nonparametric kernel regression estimator developed by Racine and $\mathrm{Li}$ [17] and Li and Racine [13] as implemented in Hayfield and Racine's R np package [10] to estimate Model 6 and subsequently derive $\hat{U}$. This estimator is not a panel data estimator, therefore it treats each of our 707 observations as 
independent, presumably leading to inflated significance and potentially inconsistent results (if a fixed effects model is appropriate). However, since we use only the residuals from that regression, and since it is likely that the random effects model is appropriate, not addressing the panel nature of the data as we did might not bear serious consequences. It is likely that the random effects model is appropriate because when one estimates Model 4 using a linear panel data estimator, the Hausman test indicates that the random-effects model is appropriate. Following Racine [16], there does not seem to be a simple panel data nonparametric estimator equivalent to the random-effects estimator.

Contrarily to Dong [7], we do not apply the Klein and Spady [12] semiparametric estimator to Model 5 because we prefer to prioritize panel data over non-parametric. Instead, we use Broström and Holmberg R glmmML package [5] to apply the panel data logit random effects estimator to the binary Model 5, including $\hat{U}$ as a regressor. Estimation results indicate that $\hat{U}$ is far from significant (55\% p-value) and that the coefficients of the other regressors (those of Table 2) change very little. We conclude that the mimic regressor $Y$ is not endogenous.

The absence of endogeneity gives a causal sense to the mimic regressor in the sense that changing it, for example through a public awareness campaign, certainly would cause a change in behavior. This relationship is significant (p-value much smaller than 0.05). The sign is positive ("if I think others discard in the network, it is more likely that I do it myself") and the coefficient is relatively large when compared to the dichotomous that indicate the type of waste (the other significant regressors).

Another regressor, the Willingness to change one's habits (respondents said they were "totally" ready to change), may be categorized as reputation effect in the sense of Bénabou and Tirole [3] because it is an attempt to demonstrate a form of goodwill to the outside world (or at least to the interviewer). While this regressor was not significant when the mimic regressor was not included, it turned close to significance upon inclusion.

The correlation coefficient $\rho$ between the different behaviors for different wastes is estimated at 0.18 in the last regression, which may seem relatively low. Of the two tests presented in Table 2, one indicates that $\hat{\rho}$ is significantly different from zero, while the other does not (in which case the behavior would not be correlated among types of wastes). It is therefore difficult to conclude without more data, but certainly, correlation across wastes behaviors is low, if at all present. 


\section{Conclusions}

We presented results of a survey on the behavior of discarding refuses in the home waste-waters network. We first note markedly different behaviors among different types of wastes. The respondents appear well aware of how their household discard each type of wastes. In very few cases is waste discarded via the external waste-waters network or in unspecified way (the "other" category in the questionnaire). The three major waste disposal behavior, for those wastes that could potentially end up in the waste-waters systems, are the Unsorted garbage bin, some manner of Recycling, and the home Waste-waters network. Seven categories of waste are nearly never discarded into the home network: Solid foodstuffs, Phytosanitaries, Hydrocarbons, Pharmaceuticals, Solid products of hygiene and cosmetics, Cigarette stubs, and Soil/sand. With the exception of Toilet paper rolls, solids are not discarded through the home network.

To better understand the factors that lead respondents to discard via the home network, we present the results of a panel-data random-effects logistic regression analysis. A striking result is that none of the "typical" socioeconomic regressors are near standard statistical levels, these include regressors such as age, gender, education, family composition, presence of pet, home ownership, or type of housing.

Following Bénabou and Tirole [3], we further separate regressors that might reflect "altruism / public good" and "reputational" motives for these behaviors. It is surprising that none of the regressors that might reflect an "altruism / public good" motive are significant; these include the respondent's knowledge of the waste-waters system (where do sewers go, what is a treatment plant for), time span living in the region, having water-based recreational activities, or being concerned by water pollution. The latter is actually close to significance (pvalue .13) so that a larger sample might be necessary to be more decisive. Therefore, it does not seem possible to influence the behavior of discarding in the home waste-waters system through the "altruism / public good" motives; we also argue that the non-point source pollution nature of home waste-waters refuses rules out any "monetary" leverage on such behavior.

Two regressors reflect reputational motives : Willingness to change one's habits and Whether the respondent thinks that his relatives and neighbors reject the corresponding waste category in the home waste-waters network. The former is close to significance (p-value at .12) while the later is the only regressor that has a clearly significant effect, in addition to the dichotomous variables indicating each waste category. In other words, when a respondent thinks her neighbors or relatives discard a particular type of waste through the home waste-waters, it is much more likely she does it herself for the same waste, a form of imitation. We have used Dong's test 
[7] to show that that regressor is not endogenous, even though we do not have an instrument. We interpret our results, at least in part, in a causal sense, that is to say, it is not because a respondent discards a particular type of waste in the home waste-waters network that she will declare that her neighbors and relatives do likewise, in a attempt to justify herself.

Therefore, if we can influence the perception of what neighbors and relatives discard in the home waste-waters network, we could likely influence discharges into that network. That seems to be the realm of the "nudges" presented in e.g. [19] or [11]: no regulations or conventional (tax/subsidy) incentives, but behavioral reference points that will guide people's behavior. The present study does not determine what form such nudge should take; we certainly could think about well-known campaigns like those on the proportion of the population that recycles batteries or lightbulbs. Our results clearly suggest that the most effective topic will likely be the behavior of neighbors and relatives, and not, for example, the effects on the environment, or images of water pollution.

Regressor "Neighbors and relatives reject corresponding waste in home waste-waters network" is certainly rough, it can only be a reflection of a broader "social network" reality in which one's behaviors about wastes are partially known to a group of people, who may be one's neighbors or relatives. A better understanding of these mechanisms, on the frontier between economics and psychology, could certainly help to better target public awareness campaigns. It is certainly surprising that such a regressor is not endogenous; it would certainly be interesting to see whether a similar exogeneity arises in comparable surveys, such as [4] and [8]. 


\section{References}

[1] James Andreoni. Impure altruism and donations to public goods: A theory of warm-glow giving. Economic Journal, 100(401):464-77, 1990.

[2] BBC. Britain's biggest 'fatberg' removed from london sewer, August 2013.

[3] Roland J. Bénabou and Jean Tirole. Incentives and prosocial behavior. IZA Discussion Papers 1695, Institute for the Study of Labor (IZA), 2005.

[4] Kjell Arne Brekke, Gorm Kipperberg, and Karine Nyborg. Social interaction in responsibility ascription: The case of household recycling. Land Economics, 86(4):766-784, 2010.

[5] Göran Broström and Henrik Holmberg. glmmML: Generalized linear models with clustering, 2011. R package version 0.82-1.

[6] A. Colin Cameron and Pravin K. Trivedi. Microeconometrics Methods and Applications. Cambridge University Press, 2005.

[7] Yingying Dong. Endogenous regressor binary choice models without instruments, with an application to migration. Economics Letters, 107(1):33 - 35, 2010.

[8] Ida Ferrara and Paul Missios. A cross-country study of household waste prevention and recycling: Assessing the effectiveness of policy instruments. Land Economics, 88(4):710-744, 2012.

[9] J. A. Hausman. Specification tests in econometrics. Econometrica, 46:1251-1271, 1978.

[10] Tristen Hayfield and Jeffrey S. Racine. Nonparametric econometrics: The np package. Journal of Statistical Software, 27(5), 2008.

[11] Peter John, Graham Smith, and Gerry Stoker. Nudge nudge, think think: Two strategies for changing civic behaviour. The Political Quarterly, 80(3):361-370, 2009.

[12] R. W. Klein and R. H. Spady. An efficient semi-parametric estimator for binary response models. Econometrica, 61:387-423, 1993.

[13] Qi Li and Jeffrey S. Racine. Cross-validated local linear nonparametric regression. Statistica Sinica, 14(2):485-512, 2004.

[14] OECD. Household Behaviour and the Environment : Reviewing the Evidence. OECD, 2008. 
[15] Elinor Ostrom. Governing the Commons: The Evolution of Institutions for Collective Action. Cambridge University Press, 1990.

[16] Jeffrey S. Racine. Nonparametric econometrics: A primer. Foundations and Trends in Econometrics, 3(1):1-88, 2008.

[17] Jeffrey S. Racine and Qi Li. Nonparametric estimation of regression functions with both categorical and continuous data. Journal of Econometrics, 119(1):99 - 130, 2004.

[18] Kathleen Segerson. Uncertainty and incentives for nonpoint pollution control. Journal of Environmental Economics and Management, 15:87-98, 1988.

[19] Richard H. Thaler and Cass R. Sunstein. Nudge: Improving Decisions about Health, Wealth, and Happiness. Yale University Press, 2008. 